\title{
LUT
}

University

\section{Serious Games for Decision-Making Processes: A Systematic Literature Review}

Rissanen Matti, Metso Lasse, Elfvengren Kalle, Sinkkonen Tiina

This is a Author's accepted manuscript (AAM) version of a publication

published by Springer

in Liyanage J., Amadi-Echendu J., Mathew J. (eds) Engineering Assets and Public Infrastructures in the Age of Digitalization. Lecture Notes in Mechanical Engineering.

DOI: 10.1007/978-3-030-48021-9_37

Copyright of the original publication: (c) Springer Nature 2020

Please cite the publication as follows:

Rissanen, M., Metso, L., Elfvengren, K., Sinkkonen ,T. (2020). Serious Games for DecisionMaking Processes: A Systematic Literature Review. In: Liyanage J., Amadi-Echendu J., Mathew $\mathrm{J}$. (eds) Engineering Assets and Public Infrastructures in the Age of Digitalization. Lecture Notes in Mechanical Engineering. Springer, Cham. DOI: 10.1007/978-3-030-48021-9_37

This is a parallel published version of an original publication. This version can differ from the original published article. 


\title{
Serious games for decision-making processes: a systematic literature review
}

\author{
Matti Rissanen ${ }^{\text {, Lasse Metso }}{ }^{1}$, Kalle Elfvengren${ }^{1}$, Tiina Sinkkonen1
}

\begin{abstract}
In asset management one key element is the availability of information at right time for decision-making. Decision-making processes in organizations are often multi-actor problems. Studies to train and improve decision-making with serious games have been previously conducted. The term "serious game" describes an intention of the player or the developer of the game to include a purpose other than pure entertainment into the game. Serious games communicate their purpose to the player through immersive and fun gameplay. While being engaged in gameplay, the players are knowingly or subconsciously more receptive to learning and skill acquisition. The number of articles about serious games in decision-making has increased during recent years. In this study, a systematic literature review is performed by using the Scopus database. The purpose of the paper is to categorize and analyse the content of existing literature of serious games for decision-making processes in organizations. The paper also raises some points on what the current games lack considering organizational and technological trends.
\end{abstract}

Keywords: serious games, decision-making, decision support, simulation games.

\section{Introduction}

Physical asset management can be seen as a process of identification, design, construction, operation and maintenance of assets. Management of critical assets requires reliable information for the decision-making process. (Faiz and Edirisinghe, 2009) Better decision-making can be done by using better and more efficient information management (Vanier, 2001). Serious games and games for learning in general are mostly used for knowledge acquisition but they have been

M. Rissanen ( $₫)$, email: matti.rissanen@lut.fi

L. Metso, email: lasse.metso@lut.fi

K. Elfvengren, email: kalle.elfvengren@lut.fi

T. Sinkkonen, email: tiina.sinkkonen@lut.fi

${ }^{1}$ Lappeenranta University of Technology, Industrial Engineering and Management, Finland 
successfully used also for example for skill acquisition and behavior change (Boyle et al., 2016).

Serious games are an approach for incorporating learning or training purpose in a fun and engaging game. Zyda (2005) defines a serious game as a mental contest where through entertaining gameplay the players' achieve a learning purpose built into the game. Playing any kind of a game is based on making series of decisions in the environment of the game. Abt (1970) mentions that testing different choices of decisions is too expensive and risky in many industrial and governmental settings due to complexity and incomplete information and serious games provide a way to compare alternatives. With serious games, complex decision-making processes can be simulated, trained and improved.

Conducting a preliminary literature review to support the design of a collaborative serious game for supporting inter-organizational decision-making processes in business ecosystems proved to be difficult. This systematic literature review investigates how serious games are used to support decision-making processes in organizations and aims to either support further research in the field of serious games in inter-organizational collaboration between companies or to reveal a gap in academic literature regarding such games.

In the Scopus database, over 200 papers can be found about supporting decisionmaking with a serious game between the years 2003 and 2017. A general conclusion after reviewing the large number of articles is that serious games are relevant for educational purposes as well as training decision-making in organizations. Serious games offer a possibility to learn and test complex decision-making situations in many different fields by simulating decision processes and studying the data of users' interactions. This literature review excludes serious game research concentrating purely on educational purposes because there is previous research on these topics with various other terms such as educational games or game-based learning.

\section{Research design}

Scopus database was used to search with string "TITLE-ABS-KEY ( ( "serious game" AND "decision making") AND NOT ("education" AND NOT "training" ))". This produced 197 search results that were screened out down to a final sample for analysis. As serious game as a term is used to also describe games with a purely educational use, these articles were excluded from the search but separately processed. Other searches were conducted in Scopus, Google Scholar and Google search engine to get a wider understanding to the topic in hand. For example, including other game terms "simulation game", "video game" and "computer game" in the search increased the amount of results in Scopus to 926. The other game terms steered the results too far from the training of decision-making processes and therefore the presented search string was deemed suitable for the purpose of this research. 
The 197 search results were first combed through on abstract level and 82 of them were excluded from the review due to not presenting a specific game or decision-making process in organizational context. The remaining 115 papers were skimmed through and 78 were removed with the same criteria as on abstract level including the removal of papers with target players being customers or patients of an organization instead of its employees, or not indicating its target players clearly. For example, a serious game dedicated to rehabilitating drug addicts might aim to improve the decision-making of the drug addict but does not directly affect the decision processes within the organization facilitating the game. Third and final screening removed 14 papers out of the remaining 37 based on the papers introducing a game too early in its concept phase for the purposes of this paper. The games too early in the concept phase would not communicate their target players or the decision-making processes included in the game and therefore making the categorizing of those papers impossible. Out of the 39 search results disregarded with the "AND NOT ("education" AND NOT "training")" part of the search string, 5 were skimmed through based on abstracts and one was chosen for the final sample. This search condition excluded papers dedicated to educational purposes but specifically included educational papers with a training purpose.

Qualitative content analysis focuses on meaning rather than quantification. Content analysis is a technique to identify reference models and to estimate parameters from textual data (Luna-Reyes and Andersen, 2003). Content analysis is a systematic research method (Krippendorff, 1980; Downe-Wambolt, 1992). Content analysis is used to analyse data, which is in textual form.

\section{Findings}

The usage of serious games to train tasks involving decision-making within organizations is gaining traction. Out of the 24 analysed papers, 17 were written during the past five years (2013-2017) and the rest between the years 2005 and 2012. The 24 papers presented 20 different serious games of which only 2 are non-digital and 18 playable with computers or mobile devices. The papers are numbered in coding by the games they present. SKYBOARD-game is presented in four papers (4a-d), D-CITE in three (7a-c) and Muller and van de Boer-Visschedijk (2017) introduces two games, BrainRun (16) and Casual Tactical Decision Game (17).

13 games have simulation as primary or secondary game genre and 7 have role play. Most primarily role playing games have simulation as a secondary genre. The distinction between simulation and role play comes from a player assuming a role, for example a physician, and playing according to the role. Simulation puts the player in the game as themselves and puts them through tasks that simulate ones from the real world. Simulation is a natural choice for training purposes as the player automatically makes the link between game and the purpose of the training in real 
life. Role play on the other hand is a genre that is used to better support the engagement and immersion to the game play, especially when the player does not practice exactly the presented task in reality. Other primary or secondary game genres recognized are quiz (3), action (1), adventure (1) and strategy (1). A quiz presents a series of questions the player answers and at the same time learns more about the topics included, action game involves fast paced situations that require swift decision-making, adventure involves different kinds of events in a game world, and strategy requires decision-making on a strategic level. All made categorizations are presented in Appendix 1.

The decision-making situations in the analysed serious games were compared with the four phases of rational decision-making: intelligence, design, choice and implementation (Turban et al., 2010). Most of the decision-making training in the analysed games belong to the design and choice phases. The design phase means that the decision-making processes under training involve inventing, developing and analysing different courses of action. In the choice phase, the player selects an action from the alternatives developed in the design phase. This is not surprising as most of the processes in the games present some form of vague emergency or critical situation, which require swift, stable and correct decision-making - for example medical complex surgery procedures or modelling decisions of a player during critical situation in supply chain management. In the intelligence phase, the player would search for conditions that require decision-making and in the implementation phase adapt the made decision. Occurrence of each phase within the analysed games is presented in table 1 . Most of the games require the player to act in more than one phase of rational decision-making.

Table 1 Occurrence of rational decision-making phases in analysed games.

\begin{tabular}{llll}
\hline Intelligence & Design & Choice & Implementation \\
\hline 4 & 16 & 14 & 4 \\
\hline
\end{tabular}

7 of the 20 analysed games are primarily related to healthcare, 4 to military, 3 to managing a conflict situation and 6 to other including project management, airport management, infrastructure planning, sports and financial decision-making. The use of serious games in training of tasks in the design and choice phases of rational decision-making also reflects in the fact that 14 of the games are single player and 6 multiplayer. 17 of the games are intra-organizational and only 3 involve roles of players inter-organizationally. All three inter-organizational, two of which are board games, are collaborative games. Inter-organizational collaboration is key in future. Games recognized here reflect that poorly, especially since only one game supports inter-organizational training in digital form, which is much more accessible to play than physical board game. 
The stage of the analysed game in the papers concentrates on prototype level. The scale is from a concept, a prototype, validated to released. A concept means the paper does not present any test results, only thoughts on the design of the game. A prototype includes a proper playable version of the game and a validated game has gone through tests within its intended target group or otherwise can draw reliable conclusions on achieving its purpose. A released game means that the game is commercially available. 4 papers present a concept, 13 a prototype, 5 a validated and 2 a released game.

Content analysis visualization was done by creating a word cloud using NVivo software (see Figure 1). In the word cloud, word frequency from the 24 analysed papers was examined. The most used word was game (synonyms included) with 2419 times in the analysed papers. The size of text in the word cloud tells the frequency of the word, a bigger font meaning higher frequency. The next frequent words were: learning (1698), making (1607), training (1591), design (1456), process (1228), work (1170), take (1061), results (1060), decision (1021), study (993), performance (972), player (899), control (840), management (830), and serious (801). However, a word of interest, collaboration, was far from the most frequent (collaborative (307) and $c d m(242))$. The last word in list $\left(100^{\text {th }}\right)$ was interaction.

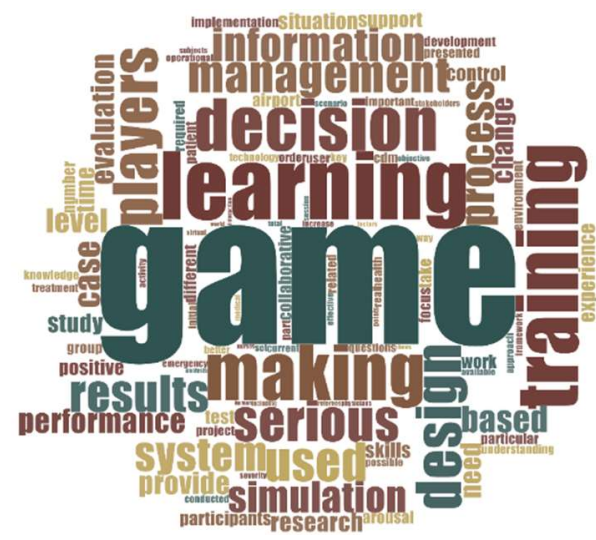

Figure 1 Word cloud

\section{Discussion and conclusions}

New and developing digital tools allow for better and more realistic simulations. Serious games including simulations in this study are still missing some elements, such as smell and feel. In "Auction Game" (Astor et al., 2013) biofeedback is used to give the player some of these missing elements but other games do not report similar usage. In addition, anon (2010) notes that serious games do not provide stimulation for all senses using the lack of the smell of a battlefield as an example from their game. 
The two most important findings were the lack of presence of the intelligence phase of the four phases of rational decision-making in the analysed games and the fact that the games concentrated on decision-making processes within a single organization. The intelligence phase includes determination of whether a problem requiring decision-making exists and the explicit definition of the possible problem. In the analysed papers, almost all of the presented games were already past this phase and the player knew the situation around which they had to make decisions. The lack of implementation phase is not as surprising since most of the games simulated this phase for the player after the player completed the choice phase. A quick glance at simulations used to optimize risk management procedures (e.g. a nuclear power plant, see Williamson et al., 2012) show that games to support the intelligence phase exist with other terminology (simulation game, simulation, gamification) than serious games, while fulfilling Zyda's (2005) definition of serious games - being entertaining and incorporating a learning purpose. Further research is required to connect the different terms to get a better understanding about using games with serious purpose to improve decision-making processes in organizations.

Inter-organizational decision process increases in complexity compared with one where the decision influences only a single organization. As Abt (1970) notes, complexity is one reason to use serious games to go through decision-making processes. However, only 3 out of the 20 analysed games involved inter-organizational decision-making. Here the further research directs towards designing and using serious games more in inter-organizational setting to test if they are indeed able to answer the issue of complexity of decision-making processes.

Decision-making in asset management requires relevant information for the basis for decisions. Serious games offer a tool for increasing the knowledge of the players about the topics they make decisions about in reality or develop the decision-making processes through simulation. Therefore, serious games are versatile in the way that they can both ensure the decision maker has the relevant information and is capable of making the decisions.

\section{References}

Abt, C., 1970. Serious Games. Reprint, University Press of America, Lanham, MD, USA, 1987.

Boyle, E. A., Hainey, T., Connolly, T. M., Gray, G., Earp, J., Ott, M., Lim, T., Ninaus, M., Ribeiro, C. and Pereira, J. (2016), 'An update to the systematic literature review of empirical evidence of the impacts and outcomes of computer games and serious games', Computers and Education, Vol. 94, pp. 178-192.

Downe-Wamboldt B., 1992. 'Content analysis: method, applications and issues', Health Care for Women International, Vol. 13 (3), pp. 313-321. 
Faiz, R.B. and Edirisinghe, E.A., 2009. 'Decision making for predictive maintenance in asset information management', Interdisciplinary Journal of Information, Knowledge, and Management, Vol. 4 (1), pp. 23-36.

Krippendorff K., 1980. Content Analysis: An Introduction to its Methodology. Sage Publications, Newbury Park, CA, USA.

Luna-Reyes, L.F. and Andersen, D.L., 2003. 'Collecting and analyzing qualitative data for system dynamics: methods and models', System Dynamics Review, Vol. 19 (4), pp. 271-296.

Turban, E., Sharda, R. and Delen, D., 2010. Decision Support and Business Intelligence Systems. 9th edition, Prentice Hall Press, Upper Saddle River, New Jersey, USA.

Vanier, D. J.,2001. 'Why industry needs management tools', Journal of Computing in Civil Engineering, Vol. 15 (1), 35-43.

Williamson, R.L., Hales, J.D., Novascone, S.R., Tonks, M.R., Gaston, D.R., Permann, C.J., Andrs, D. and Martineau, R.C., 2012. 'Multidimensional multiphysics simulation of nuclear fuel behavior', Journal of Nuclear Materials, Vol. 423 (1-3), pp. 149-163.

Zyda, M., 2005. 'From visual simulation to virtual reality to games', Computer, Vol. 38 (9), pp. 25-32. 


\section{Coded papers}

1. Astor, P.J., Adam, M.T.P., Jerčić, P., Schaaff, K. and Weinhardt, C., 2013. 'Integrating biosignals into information systems: A NeuroIS tool for improving emotion regulation', Journal of Management Information Systems, Vol. 30 (3), pp. 247-277. 2. Basole, R.C., Bodner, D.A. and Rouse, W.B., 2013. 'Healthcare management through organizational simulation', Decision Support Systems, Vol. 55 (2), pp. 552563.

3. Bekebrede, G., Mayer, I., Van Houten, S.P., Chin, R. and Verbraeck, A., 2005. 'How serious are serious games? Some lessons from infra-games', in Proceedings of DiGRA 2005 Conference: Changing Views - Worlds in Play, Vancouver, Canada. 4a. Corrigan, S., Mårtensson, L., Kay, A., Okwir, S., Ulfvengren, P. and McDonald, N., 2015. 'Preparing for Airport Collaborative Decision Making (A-CDM) implementation: an evaluation and recommendations', Cognition, Technology and Work, Vol. 17 (2), pp. 207-218.

4b. Corrigan, S., McDonald, N., Zon, R., Maij, A. and Mårtensson, L., 2013. 'Collaborative learning \& serious game development', in Proceedings of the SESAR Innovation Days 2013, Stockholm, Sweden.

4c. Corrigan, S., Zon, G.D.R., Maij, A., McDonald, N. and Mårtensson, L., 2015. 'An approach to collaborative learning and the serious game development', Cognition, Technology and Work, Vol. 17 (2), pp. 269-278.

4d. Zon, R., Corrigan, S., McDonald, N. and Maij, A., 2012. 'A Learning, training $\&$ mentoring framework (LTM) \& the role of serious games to facilitate sustainable change in the aviation industry', in Proceedings of 11th International Probabilistic Safety Assessment and Management Conference and the Annual European Safety and Reliability Conference 2012, PSAM11 ESREL 2012, Helsinki, Finland.

5. Crozier, M.D., Moore, A.P. and Verna, T.M., 2010. 'Serious games for first person 'thinker', in Proceedings of Spring Simulation Multiconference 2010, SpringSim'10, Orlando, FL, USA.

6. Ferretti, I., Mazzoldi, L., Zanoni, S. and Zavanella, L., 2016. 'Learning effects in professional training for emergencies management in industrial plants with serious games', in Proceedings of 5th International Workshop on Innovative Simulation for Health Care, IWISH 2016, Larnaca, Cyprus.

7a. Freese, M., 2016. 'Game-based learning: An approach for improving collaborative airport management', in Proceedings of the European Conference on Gamesbased Learning, Paisley, United Kingdom.

7b. Freese, M. and Drees, S., 2016. 'D-CITE - A serious game to analyze complex decision-making in air traffic management', in De Gloria A., Veltkamp R. (eds) Games and Learning Alliance. GALA 2015. Lecture Notes in Computer Science, Vol. 9599, Springer, Cham, Switzerland.

7c. Schier, S., Freese, M. and Mühlhausen, T., 2016. 'Serious gaming in airport management: Transformation from a validation tool to a learning environment', in Bottino R., Jeuring J., Veltkamp R. (eds) Games and Learning Alliance. GALA 2016. Lecture Notes in Computer Science, Vol. 10056, Springer, Cham, Switzerland. 
8. Graafland, M., Vollebergh, M.F., Lagarde, S.M., Van Haperen, M., Bemelman, W.A. and Schijven, M.P., 2014. 'A serious game can be a valid method to train clinical decision-making in surgery', World Journal of Surgery, Vol. 38 (12), pp. 3056-3062.

9. Gulec, U. and Yilmaz, M., 2016. 'A serious game for improving the decision making skills and knowledge levels of Turkish football referees according to the laws of the game', SpringerPlus, Vol. 5 (1).

10. Jarvis, S. and De Freitas, S., 2009. 'Evaluation of an immersive learning programme to support triage training: In-game feedback and its effect on learning transfer', in Proceedings of the 2009 Conference in Games and Virtual Worlds for Serious Applications, VS-GAMES 2009, Coventry, United Kingdom.

11. Kurapati, S., Kolfschoten, G., Verbraeck, A., Corsi, T.M. and Brazier, F., 2013. 'Exploring shared situational awareness in supply chain disruptions', in ISCRAM 2013 Conference Proceedings - 10th International Conference on Information Systems for Crisis Response and Management, Baden-Baden, Germany.

12. Lelardeux, C.P., Panzoli, D., Lagarrigue, P. and Jessel, J., 2016. 'Making decisions in a virtual operating room', in Proceedings of 2016 International Conference on Collaboration Technologies and Systems, CTS 2016, Orlando, FL, USA.

13. MacKinnon, L. and Bacon, L., 2012. 'Developing realistic crisis management training', in ISCRAM 2012 Conference Proceedings - 9th International Conference on Information Systems for Crisis Response and Management, Vancouver, Canada. 14. Mohan, D., Rosengart, M.R., Fischhoff, B., Angus, D.C., Farris, C., Yealy, D.M., Wallace, D.J. and Barnato, A.E., 2016. 'Testing a videogame intervention to recalibrate physician heuristics in trauma triage: Study protocol for a randomized controlled trial', BMC Emergency Medicine, Vol. 16 (1).

15. Monga, C., Jain, J., Kumar, S. and Sandeep, A., 2017. 'Context rich digital games for better learnability in the IT project management context', in Proceedings of the 9th International Conference on Computer Supported Education CSEDU 2017, Porto, Portugal.

16 \& 17. Muller, T. and Van De Boer-Visschedijk, G., 2017. 'Mobile gaming for military: Two case studies', in Proceedings of the 11th European Conference on Games Based Learning, ECGBL 2017, Graz, Austria.

18. Ribeiro, C., Monteiro, M., Pereira, J.M., Antunes, T. and Hauge, J.B., 2014. 'Sepsis fast track: A serious game for medical decision making', in Ma M., Oliveira M.F., Baalsrud Hauge J. (eds) Serious Games Development and Applications. SGDA 2014. Lecture Notes in Computer Science, Vol. 8778, Springer, Cham, Switzerland.

19. Vidani, A.C., Chittaro, L. and Carchietti, E., 2010. 'Assessing nurses' acceptance of a serious game for emergency medical services', in Proceedings of 2nd International Conference on Games and Virtual Worlds for Serious Applications, VS-GAMES 2010, Braga, Portugal.

20. anon, 2010. 'Serious Games and Tactical decision making training', in Proceedings of Spring Simulation Multiconference 2010, SpringSim'10, Orlando, FL, USA. 
10 M.Rissanen - Serious games for decision-making processes: a systematic literature review Appendix 1. Categorization of serious games for decision-making.

\begin{tabular}{|c|c|c|c|c|c|c|c|c|c|c|c|c|c|c|c|c|c|c|c|}
\hline \multirow[t]{2}{*}{ 坖 } & \multicolumn{2}{|c|}{ 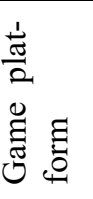 } & \multicolumn{2}{|c|}{ 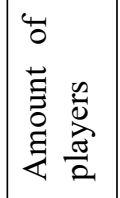 } & \multicolumn{2}{|c|}{ 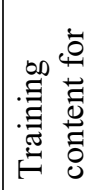 } & \multicolumn{4}{|c|}{ 芯 } & \multicolumn{5}{|c|}{ 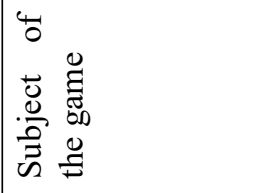 } & \multicolumn{4}{|c|}{ 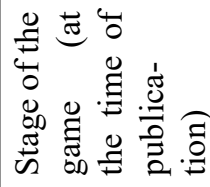 } \\
\hline & 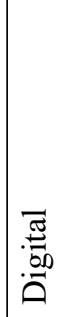 & 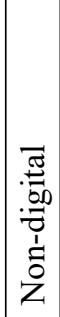 & 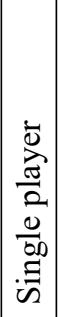 & 㐫 & 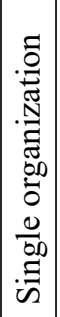 & 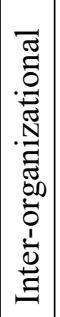 & 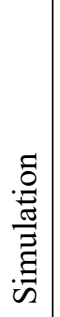 & 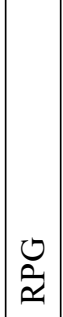 & $\stackrel{ }{\partial}$ & $\begin{array}{l}\dot{\overline{0}} \\
\overline{\mathscr{D}} \\
\end{array}$ & 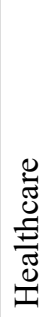 & 忌 & 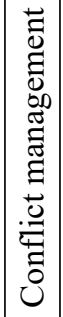 & 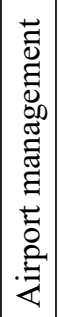 & 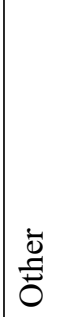 & 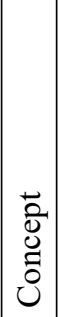 & $\begin{array}{l}0 \\
2 \\
2 \\
0 \\
0 \\
0 \\
0 \\
0\end{array}$ & 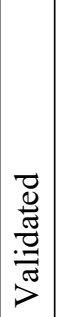 & 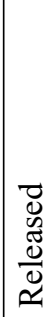 \\
\hline 1 & $\mathrm{X}$ & & $\mathrm{X}$ & & $\mathrm{x}$ & & & 1 & & & & & & & 1 & & & $\mathrm{x}$ & \\
\hline 2 & $\mathrm{X}$ & & $\mathrm{X}$ & & $\mathrm{X}$ & & 1 & & & & 1 & & & & 2 & & & $\mathrm{X}$ & \\
\hline 3 & $\mathrm{X}$ & & & $\mathrm{x}$ & $\mathrm{X}$ & & 1 & & & & & & & & 1 & $\mathrm{x}$ & & & \\
\hline $4 a$ & & $\mathrm{x}$ & & $\mathrm{X}$ & & $\mathrm{x}$ & 2 & 1 & & & & & & 1 & & $\mathrm{X}$ & & & \\
\hline $4 b$ & & $\mathrm{x}$ & & $\mathrm{X}$ & & $\mathrm{x}$ & 2 & 1 & & & & & & 1 & & & $\mathrm{x}$ & & \\
\hline $4 c$ & & $\mathrm{x}$ & & $\mathrm{X}$ & & $\mathrm{X}$ & 2 & 1 & & & & & & 1 & & & & $\mathrm{X}$ & \\
\hline $4 d$ & & $\mathrm{X}$ & & $\mathrm{X}$ & & $\mathrm{X}$ & 2 & 1 & & & & & & 1 & & $\mathrm{X}$ & & & \\
\hline 5 & $\mathrm{x}$ & & & $\mathrm{X}$ & $\mathrm{X}$ & & 1 & & & & & 1 & & & & & & & $\mathrm{x}$ \\
\hline 6 & $\mathrm{X}$ & & $\mathrm{X}$ & & $\mathrm{X}$ & & 2 & 1 & & & 2 & & 1 & & & & $\mathrm{X}$ & & \\
\hline $7 \mathrm{a}$ & $\mathrm{x}$ & & & $\mathrm{x}$ & & $\mathrm{x}$ & 2 & 1 & & & & & & 1 & & & $\mathrm{X}$ & & \\
\hline $7 b$ & $\mathrm{x}$ & & & $\mathrm{X}$ & & $\mathrm{X}$ & 2 & 1 & & & & & & 1 & & & $\mathrm{X}$ & & \\
\hline $7 \mathrm{c}$ & $\mathrm{X}$ & & & $\mathrm{X}$ & & $\mathrm{X}$ & 2 & 1 & & & & & & 1 & & & $\mathrm{X}$ & & \\
\hline 8 & $\mathrm{x}$ & & $\mathrm{x}$ & & $\mathrm{X}$ & & & & 1 & & 1 & & & & & & $\mathrm{x}$ & & \\
\hline 9 & $\mathrm{x}$ & & $\mathrm{X}$ & & $\mathrm{X}$ & & & & 1 & & & & & & 1 & & & $\mathrm{x}$ & \\
\hline 10 & $\mathrm{x}$ & & $\mathrm{X}$ & & $\mathrm{X}$ & & 1 & & & & 1 & & & & & & & $\mathrm{X}$ & \\
\hline 11 & & $\mathrm{X}$ & & $\mathrm{X}$ & & $\mathrm{X}$ & 2 & 1 & & & & & 1 & & & & $\mathrm{X}$ & & \\
\hline 12 & $\mathrm{x}$ & & & $\mathrm{x}$ & $\mathrm{X}$ & & 1 & & & & 1 & & & & & & $\mathrm{X}$ & & \\
\hline 13 & $\mathrm{x}$ & & $\mathrm{X}$ & & $\mathrm{X}$ & & 1 & & & & & & 1 & & & $\mathrm{X}$ & & & \\
\hline 14 & $\mathrm{x}$ & & $\mathrm{X}$ & & $\mathrm{X}$ & & & 2 & & 1 & 1 & & & & & & $\mathrm{x}$ & & \\
\hline 15 & $\mathrm{x}$ & & $\mathrm{X}$ & & $\mathrm{X}$ & & 2 & 1 & & & & & & & 1 & & $\mathrm{X}$ & & \\
\hline 16 & $\mathrm{x}$ & & $\mathrm{X}$ & & $\mathrm{X}$ & & & & 1 & & & 1 & & & & & $\mathrm{X}$ & & \\
\hline 17 & $\mathrm{x}$ & & $\mathrm{X}$ & & $\mathrm{X}$ & & & & & 1 & & 1 & & & & & $\mathrm{X}$ & & \\
\hline 18 & $\mathrm{x}$ & & $\mathrm{x}$ & & $\mathrm{X}$ & & 1 & & & & 1 & & & & & & $\mathrm{x}$ & & \\
\hline 19 & $\mathrm{x}$ & & $\mathrm{X}$ & & $\mathrm{X}$ & & 1 & & & & 1 & & & & & & $\mathrm{X}$ & & \\
\hline 20 & $\mathrm{x}$ & & $\mathrm{X}$ & & $\mathrm{x}$ & & 1 & & & & & 1 & & & & & & & $\mathrm{x}$ \\
\hline
\end{tabular}

$1=$ primary, 2 = secondary 